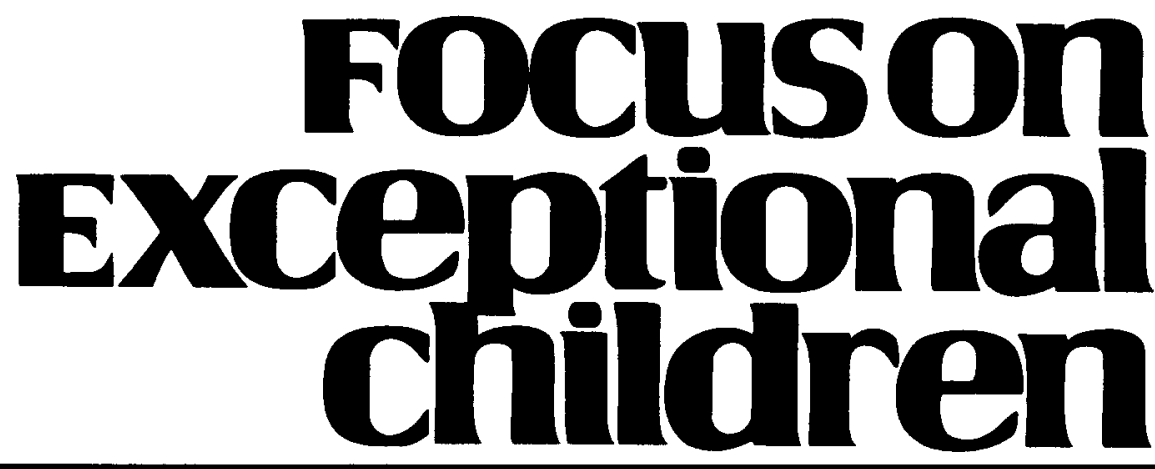

\title{
The Disruptive or ADHD Child: What to Do When Kids Won't Sit Still and Be Quiet
}

\author{
Mary N. Cook, $M D$
}

Successful intervention for severely disruptive children is likely to require effort and collaboration among pediatric mental health specialists, parents, and school staff. Children with severe disruptive behavior disorders usually require follow-up with credentialed pediatric mental health specialists and may need special classrooms, schools, or even residential treatment centers. Still, school counselors often find themselves as the first line of defense with these children. Children who disrupt the classroom may have a variety of psychiatric disorders, including attention deficit hyperactivity disorder (ADHD), oppositional defiant disorder (ODD), and conduct disorder (CD).

\section{ATTENTION DEFICIT HYPERACTIVITY DISORDER}

The usual figure for prevalence for ADHD is 3\% to 5\% of school-aged children (Cantwell, 1996). It is fairly clear from genetic and brain imaging studies that ADHD is a brain disorder, not a disorder caused by parenting or other environmental factors. ADHD clearly runs in families, with heritability estimates ranging from .55 to .92 . On average, $25 \%$ of immediate family members of children with ADHD are likely to have the disorder. Put another way, there is a $50 \%$ chance that one of the ADHD child's parents will also have the disorder. Psychosocial factors are not thought to play a primary etiological role.

Studies reveal that stimulant medications are a robust and safe treatment for ADHD with no significant long-term ill effects, including no significant impact on growth. Some studies have even revealed that stimulant medications used for ADHD may have a protective effect in terms of decreasing the risk of substance abuse in treated ADHD patients, when compared to their untreated counterparts. The core criteria for ADHD come in two categories: inattentive and impulsive-hyperactive criteria. They include disorganization, distractibility, forgetfulness, tendency to lose things, seeming not to listen, overactivity, fidgetiness, excessive talkativeness, failure to remain seated, blurting things out, and interrupting.

Mary N. Cook, MD, is board-certified in child and adolescent psychiatry and general psychiatry. She works at the University of Colorado Health Sciences Center in Denver. This article was adapted from a chapter in her book (coauthored with Kathy Weldon, MA) entitled Counseling Kids With Emotional and Behavioral Problems in the Schools, published by Love Publishing Company. 
Children with ADHD are likely to have comorbid psychiatric disorders, including learning disabilities, ODD, CD, anxiety, depression, and substance abuse. Up to $65 \%$ of children with ADHD are likely to have ODD as well. It is important, after an ADHD diagnosis has been established, to rule out other diagnostic entities. At the school in particular, the child should be assessed for a learning impairment. Children with ADHD are also likely to be rejected socially: They tend to misinterpret social cues in an overly hostile way, interrupt, butt ahead, refuse to follow game rules, and make offensive remarks impulsively. Studies reveal that children with comorbid problems, particularly social impairment, anxiety, and oppositionality, are likely to benefit from the addition of intensive behavior modification.

The clinical lore used to be that ADHD children outgrew their disorder. Studies now reveal that this lore was false, that children do seem to outgrow the hyperactivity symptoms, which begin dissipating around age 11 , as well as their impulsivity symptoms, which typically begin to fade around age 13. But a significant portion of children with ADHD - perhaps half - continue to manifest clinically significant levels of inattention into adolescence and young adulthood.

\section{Focuson
Exceptional
children} ISSN 0015-511X FOCUS ON EXCEPTIONAL CHILDREN (USPS 203-360) is published monthly except June, July, and August as a service to teachers, special educators, curriculum specialists, administrators, and those concerned with the special education of exceptional children. This publication is annotated and indexed by the ERIC Clearinghouse on Handicapped and Gifted Children for publication in the monthly Current Index to Journals in Education (CIJE) and the quarterly index, Exceptional Children Education Resources (ECER). The full text of Focus on Exceptional Children is also available in the electronic versions of the Education Index. It is also available in microfilm from Xerox University Microfilms, Ann Arbor, MI. Subscription rates: individual, \$36 per year; institutions, \$48 per year. Copyright (C) 2005, Love Publishing Company. All rights reserved. Reproduction in whole or part without written permission is prohibited. Printed in the United States of America. Periodical postage is paid at Denver, Colorado. POSTMASTER: Send address changes to:

$$
\begin{gathered}
\text { Love Publishing Company } \\
\text { Executive and Editorial Office } \\
\text { P.O. Box } 22353 \\
\text { Denver, Colorado } 80222 \\
\text { Telephone (303) } 221-7333
\end{gathered}
$$

Susan T. Warhover Editor
Stanley F. Love

Publisher

\section{OPPOSITIONAL DEFIANT DISORDER}

Like ADHD, ODD tends not to occur by itself. Up to $30 \%$ of children with ODD also have ADHD. ODD children are likely to also have problems with learning, anxiety, or depression, or may go on to develop conduct disorder. ODD is found in $5 \%$ to $15 \%$ of school-aged boys and $1 \%$ to $4 \%$ of school-aged girls, demonstrating a clear predilection for afflicting boys. The criteria for ODD include a negativistic, hostile attitude, tendency to lose temper, argumentativeness, defiance, deliberate annoying of others, and vindictiveness. ODD children are at higher risk to develop conduct disorder, a more serious disorder associated with criminality, substance abuse, and violation of the rights of others.

Two empirically validated intensive behavioral programs currently are available for the treatment of ODD. These include parent management training (Barkley, 1997) and collaborative problem solving (Greene, 2001). The program developed by Greene is particularly designed for implementation in the schools, although a manual for his program is not yet available:

\section{CONDUCT DISORDER}

Conduct disorder, like ODD, tends to affect more boys than girls, with prevalence rates of $5 \%$ to $16 \%$ in school-aged boys, versus $1 \%$ to $4 \%$ in girls. The hallmarks of CD are bullying, physical fights, using a weapon, cruelty to animals and people, forced sexual activity, property destruction, lying, stealing, fire setting, truancy, and running away. $\mathrm{CD}$, as well as ODD, is more prevalent in families of lower socioeconomic status. Several psychiatric disorders are associated with $\mathrm{CD}$, including ADHD, substance abuse, depression, mania, schizophrenia, and ultimately, antisocial personality disorder, which is roughly equivalent to sociopathy. Depression in particular is highly associated with $\mathrm{CD}$, with some studies quoting rates of up to $60 \%$ of youth with $\mathrm{CD}$ having comorbid depression. The prognosis for conduct disorder, especially with onset before age 10 , is bleak. Children with conduct disorder, especially if they develop comorbid depression or substance abuse problems, are likely to be refractory to intervention and are at higher risk for legal, occupational, and marital problems. Early, aggressive, multimodal intervention affords the best prognosis for youth with $\mathrm{CD}$.

\section{ASSESSMENT}

The worst source of information for children suspected of having impulse control or disruptive behavior problems is the children themselves. Children with disruptive behavior disorders tend to be emotionally immature and lack insight regarding their behaviors and feelings. They tend to 
externalize or have an external locus of control, and typically blame teachers, parents, peers, or the dog for their misbehavior or academic failure. They have difficulty taking personal responsibility for their behavior and recognizing any role they might have played in a conflict situation. They tend to misinterpret social cues in general, and in particular they are likely to interpret neutral stimuli in an overly negative, hostile, or threatening way. For instance, a child with ADHD or ODD is more likely to assume. hostile intent when bumped in line by a peer than does a child without ADHD.

Of course, interviewing the child provides some useful information. In particular, it helps the evaluator understand the child's perspective, feelings, concerns, and psychological defenses. In terms of collecting data to support a disruptive behavior disorder, the best investment is in collateral sources, that is, obtaining feedback from teachers and parents or other caregivers. Direct classroom or playground observations can be helpful, too, but are not always feasible or practical.

Rating scales such as the Parent and Teacher Conners Scales (Conners, 1997) and the Child Behavior Checklist (Achenbach \& Edelbrock, 1991) are very valuable in assessing for disruptive behaviors and associated symptoms. These are commercially available, easy to use, and require no special training. They can be obtained initially as part of a preliminary work-up and repeated over time to assess response to treatment-in particular medication treatment of ADHD.

As mentioned previously, children with ADHD are at risk for learning disorders. It is therefore important to screen those who are struggling academically for learning disabilities.

\section{INTERVENTIONS}

Disruptive children often have problems getting along with adults and peers. They typically have problem-solving deficits and trouble controlling their anger. They often misinterpret social cues and annoy and offend others. Therefore, disruptive children would benefit from some social skills training. In particular, they struggle with expressing negative feelings in a safe and appropriate way and resolving social conflict. Assertiveness training is extremely helpful for these children. You can suggest to these disruptive children that they will be more successful at getting what they want and keeping friends if they learn to use their words and not their fists to vent anger. In addition, children with a pattern of explosive anger can be taught relaxation techniques to control their anger and can be cued to "take a cool down" when they are beginning to get agitated. The following interventions are also helpful.

\section{Anger Management Training}

Initially, when working with children who are thought to have anger management problems that show up in the form of tantrums, verbal or physical aggression, or property destruction, the key is to understand as much as possible about the child and his or her anger triggers. Anger and fear or anxiety are thought to be closely linked reactions and both produce an adrenaline response. Anger might be thought of as fear or anxiety turned out and anxiety might be thought of as anger turned in. Essentially, kids (and adults) express anger when they feel threatened. When they fear their needs won't get met, they get mad.

Kids who are at risk for having problems with inappropriate and explosive expression of anger include those with ADHD because they are impulsive and often don't think before they react. Also at risk are kids with learning problems and language delays. These children might not have the words to communicate their needs effectively or the know-how to get what they need in an adaptive way. Children with autism often exhibit explosive aggression, probably secondarily to their limited language abilities.

You can begin by talking to the parents, teacher, and the child to learn about that child's particular triggers. Performing classroom and playground observations can also be helpful.

When you begin with a child or group of children, begin by talking about anger in general. You want to be clear that experiencing anger, even on a daily basis, is perfectly normal. You want to be sure they don't become ashamed about their anger and that they understand that expression of anger is normal and healthy. You can tell them that to experience transient wishes to harm others, in the heat of anger, is perfectly normal and common. They can fantasize about anything they want, just so long as wishes to harm others remain a fantasy. Tell them about ambivalence in relationships, that is, that we all sometimes feel angry even at people we love. All relationships and all people are a mix of good and bad, and just because we sometimes get angry, even at people we love, doesn't mean we're bad or that we don't love someone.

Ask them if anger is ever a good thing. Ask for examples. They should arrive at the notion that anger is sometimes helpful and fuels change. If we're mad enough about an injustice, we work hard to try to make things right. You can bring up examples from history, such as the actions of Rosa Parks and Martin Luther King, Jr.

Have the child or group of children brainstorm a list of signals that cue them that they're angry.

The list might look like this:

My face turns red.

I feel sick to my stomach.

My fists ball up.

I get sweaty.

I clench my teeth. 
I want to kill somebody.

My muscles tense up.

I start screaming.

The idea is to help kids recognize anger early and identify patterns in their development of anger. What kinds of things set them off? Again, here's an opportunity to point out how we all perceive the same situation differently and different things make different people angry. Many kids with explosive aggression and severe tantrums find it difficult to de-escalate their reactions after they've blown a fuse. The idea is to be proactive in identifying anger triggers and heading them off before they escalate. Also, if children become more tuned into their body signals, they can take care of themselves and deal with the anger and the precipitant for their anger before they blow.

Ask kids to give examples of explosive anger from their own experiences or imaginations. Write each example on the board and have them generate a list of potential longterm and short-term consequences, both positive and negative, for each instance of explosive aggression.

The next step is to teach them some immediate ways of getting control of their anger, before it builds to the point of no return. Relaxation training is invaluable for children with explosive anger. It is a must for all kids who undergo anger management training. Children should be encouraged to practice relaxation daily, which will result in a lowering of their baseline level of tension, and to employ relaxation when they begin to feel angry or anxious. You can point out that these exercises require no equipment and are free. Children can be cued by parents and teachers initially (the idea is for them to eventually cue themselves) to take a "cooldown" (sounds better than "time-out," which has punitive implications).

\section{Problem-Solving Skills Training}

Problem-solving skills are especially important for children who have trouble with inappropriate expressions of anger. After children have taken a cooldown and feel in control enough to reason and talk, they can be encouraged to problem solve. When they are ready to problem solve around a social conflict, the counselor's role should be to guide and support, but not direct. The idea is to guide the child to become an independent thinker and problem-solver who makes good choices, whether you're in the room or not. The counselor can introduce the steps of problem solving, easily remembered with the fun pneumonic D.I.R.T.:

\footnotetext{
$\mathrm{D}=$ Define, as in define the problem

I = Identify, as in identify choices

$\mathrm{R}=$ Reflect, as in reflect on the choices

$\mathrm{T}=$ Try, as in try it out
}

The idea is to help children brainstorm, when they are coolheaded, as many options as possible for approaching a given problem. Then the counselor can encourage them to 'work through their options mentally, choose one, and then try it out. The goal, through diligent practice and rehearsal, is to have these skills become second nature.

\section{Define the Problem}

The first step with children who are upset is to help them ralk out their feelings and cool down. Sometimes it's helpful to assist them in performing relaxation exercises. Expressions of empathy and support from the counselor can also diffuse upset children. The goal is to help them arrive at a point where the intensity of the feelings is no longer overwhelming and they feel back in control. As their level of arousal is lowered and their brains begin to reason, help them define the problem as specifically as possible.

\section{Identify Choices}

When children are ready, encourage them to use their "good brains" to identify options for approaching the problem. During the brainstorming, it's helpful if the counselor writes down the child's ideas. This exercise of writing down their thoughts gives validity and weight to their ideas. Children should be encouraged to develop as comprehensive a list as possible and not reject or withhold any ideas initially. The counselor may contribute some ideas, too, but should be careful not to be overbearing or critical of any of the initial suggestions.

\section{Reflect on the Choices}

The next step would be to have children work through the list mentally, visualizing the likely outcome of each approach. After they have covered the list, they should be encouraged to pick the option that they think will result in the best outcome.

\section{Try It Out}

Finally, encourage them to try out their chosen option and report back to you regarding the results.

Many children who have ADHD behave aggressively. They act before thinking ahead to the consequences. The idea is to train them to become experts on slowing down and thinking before acting.

One excellent way to reinforce the concepts of problem solving is to role-play. You can hand out STOP signs to some kids and ask them to hold them up when they see a "hotheaded" response. Kids love the power inherent in holding a STOP sign, and they love to correct each other. When kids deliver a hotheaded response to a problem scenario 
during a role play, they are clowning it up and having fun so no offense is taken when others hold up their STOP signs.

You can also create a game with a set of cards that have sample problems, a set of reaction cards that say either "hotheaded" or "coolheaded," and a set of consequence cards that say "long-term" or "short-term." You can take turns if you're working individually with a child, or go around the table if working with a group. The first child draws a problem card and reads it out loud. The next child draws a reaction card (either hotheaded or coolheaded) and responds with a possible reaction to the problem card, one that fits in the proper category. Finally, the third child picks a consequence card (either long-term or short-term) and gives an example of what an immediate or longer term outcome might be, given the reaction stated by the previous child.

The following sample problems are suggested:

SAMPLE PROBLEMS FOR ROLE PLAY

\begin{tabular}{lll}
$\begin{array}{l}\text { The class bully } \\
\text { was making fun of } \\
\text { my best friend. }\end{array}$ & $\begin{array}{l}\text { Another child } \\
\text { stole my } \\
\text { Game Boy. }\end{array}$ & $\begin{array}{l}\text { My sister } \\
\text { broke my } \\
\text { Xbox. }\end{array}$ \\
\hline $\begin{array}{l}\text { I was accused of } \\
\text { cheating, but }\end{array}$ & $\begin{array}{l}\text { My mother is } \\
\text { always late to } \\
\text { pick me up. }\end{array}$ & $\begin{array}{l}\text { My friend told } \\
\text { the whole school } \\
\text { a secret of mine. }\end{array}$ \\
\hline $\begin{array}{l}\text { Another child } \\
\text { stole my money. }\end{array}$ & $\begin{array}{l}\text { Another child } \\
\text { pushed me. }\end{array}$ & $\begin{array}{l}\text { Another child } \\
\text { butted in line. }\end{array}$ \\
\hline
\end{tabular}

Three other important skills to cover with kids with explosive anger are assertiveness, conflict resolution, and the handling of teasing. You can help these children realize that their needs, wants, and feelings are important, that it's not okay for others to mistreat them. But you can offer alternatives to blowing up when they feel slighted. The idea is to teach them effective and safe ways of expressing their anger and getting what they want. At the same time, you want to help them appreciate that aggression only generates more conflicts, gets people or property hurt, gets them in trouble, and usually does not get them what they sought in the first place.

Consider the following example:

Nolan was a disruptive child. With poor impulse control and difficulty interpreting social cues, he was chronically engaging in some form of classroom altercation. A simple example that occurred with predictable regularity was Nolan's pushing in line. Typically, Nolan's pushing-orshoving behavior was in response to his perception that another child had intentionally pushed or shoved him. As a socially immature second-grader, Nolan interpreted his classmates' competitive "line up" behavior quite personally. He inevitably took offense if he was bumped or unintentionally pushed by another child as they scrambled to line up. A successful intervention occurred when the classroom participated in a role play.

He and his classmates were invited to participate in a role play in an effort to help Nolan develop more effective line behavior. As requested, the group got in a line and intentionally role-played-bumping, touching, and squeezing up against Nolan. Although the interaction was clearly simulated, Nolan's agitation quickly became apparent. A time-out was called, and Nolan was asked to consider how he was feeling. He admitted to feeling very angry. The group discussed how often they had felt wronged when others inadvertently bumped or pushed them in line. They discussed ways to deal with those feelings-using words, rather than responding physically. The role play was resumed and Nolan's reaction was significantly different. Rather than demonstrating his anger, he actually began to smile, betraying his recognition that the group was working together to solve a common dilemma. The role play was stopped and again discussed. A third time the pushing-and-shoving line-up behavior was reenacted, and Nolan breezed through the appropriate response.

Six weeks later, his teacher reported that there had been no recurrence of his violent temper in line (previously often a daily occurrence) after the intervention.

\section{CLASSROOM INTERVENTIONS FOR CHILDREN WITH ADHD}

\section{Strategies for Improving Attention}

Teachers are advised to seat children with ADHD up front, close to them, and to provide one instruction at a time, repeat the instruction, and keep all instructions brief. Assignments should be broken up into bite-size workable steps, and the child with ADHD should be asked to repeat the instructions so as to demonstrate clear understanding. Written instructions should be given along with oral instructions, and visual aides should be employed whenever possible. The child with ADHD should be taught techniques for active reading, including underlining, highlighting, or taking notes. Remedial help may be needed to ensure success for the child with ADHD.

The ADHD or disruptive child responds best to a very structured classroom setting in which rules and expectations are clear, predictable, and known in advance. Also, children with ADHD learn better in spurts and cannot track well 
during long didactic lectures. Twelve 5-minute assignments achieve more with a child with ADHD than two 30minute assignments. A child with ADHD is also helped by frequent breaks and can be invited to run errands or erase the chalkboard.

\section{Strategies for Improving Compliance}

All children, but particularly disruptive children, respond best to lots of positive reinforcement and reward for good behavior rather than scolding or punishments for negative behavior. Negative attention leads to more negative behavior, and many disruptive children seem to thrive or almost be addicted to negative attention from authority figures. These children are often experts on "pushing the buttons" of responsible adults and affecting a strong negative reaction from others. Teachers should be encouraged, if possible, to ignore low-level negative behavior. They should instead actively tune in to and praise appropriate and desired behaviors as they appear. Any approximation of desirable behavior, particularly in a typically noncompliant or disruptive child, or any improvement in behavior should be acknowledged, praised, and rewarded. If a child complies with directions but exhibits a bad attitude, the compliance should be praised and the bad attitude ignored. Obviously, unsafe behavior cannot be ignored, but in addressing these behaviors, the teacher should attempt to retain as calm a demeanor and tone of voice as possible. A teacher becoming highly agitated leads to further arousal in an already out-of-control child. The teacher may find that by simply acknowledging the child's feelings and saying nurturing, supportive things in a soft, reassuring voice, he or she can de-escalate a situation and avert a meltdown in an agitated child.

Greene (2001) has conceptualized explosive, oppositional, socially impaired children as having skills deficits. He likens the underlying cause of their behavioral and social problems to a developmental delay or learning disability. These disruptive children simply haven't yet mastered reading social cues, resolving social conflict (in a healthy, productive way), regulating their affect, and problem solving. They "melt down" when faced with social conflict or when things don't go exactly according to their plan or expectations. With this as a conceptual framework, Greene recommends parents and teachers make every effort to modify the disruptive child's environment to increase the chances for social and academic success. He advises that the grown-ups make every effort to reduce demands on children with disruptive behavior disorders. Greene and his group at Harvard University are in the process of developing a school-based, cognitive-behavioral program for explosive children, modeled on Greene's earlier collaborative problem-solving approach for parents that is detailed in his book The Explosive Child (2001). This program has been empirically validated and has actually demonstrated superior efficacy over the well-established parent training program for oppositional children developed by Barkley (1997).

\section{BEHAVIORAL CONTRACTS FOR THE CLASSROOM}

Behavioral contracts are extremely helpful in disrupting a vicious cycle of negative behavior that begets negative attention that begets negative behavior. The idea is to create a way to turn the situation around and make it more positive, build up the self-esteem of an acting-out child, and teach that child how to get positive attention. The hope is that the teacher, counselor, parents, and children involved can work toward a common, prosocial goal where everyone feels like a winner.

There are essentially three major components to an effeclive behavioral contract: identified target behaviors, a tracking system, and a rewards menu. When developing a contract, it is important for the counselor to collaborate with the teachers, parents, and child. The idea is that if the stakeholders have input into the program, they are more likely to be invested and compliant.

\section{Target Behaviors}

When developing targets, it's important to be sure you are on target and identify the most problematic behaviors. Disruptive children tend to be off task, talk excessively, or be aggressive. It is also important to identify only a few (two or three) targets at a time, to carefully pick your battles, and to set up a program that is reasonable and achievable for the child. The targets should be very specific and worded affirmatively. I have seen many school contracts where a child receives a smiley face for "being good." However, these programs mean little to a child whose version of being good might be completely different from that of an adult. Any time children who are disruptive or oppositional are told "Don't," "No," or "You can't," they are likely to resist and defy the authority figure delivering the commands. So, rather than, "Don't hit," it is better to say, "Keep your hands and feet to yourself." Rather than, "No name-calling," it is better to say, "Refer to others by their given names at all times." Rather than, "Stop talking," it is better to say, "Speak only when it's your turn." If a child refuses to follow directions, you could phrase the target behavior, "Follow directions by the count of five."

\section{Tracking}

A key ingredient to a successful behavioral program is a diligently applied tracking system. For younger children, stickers work well. For older children, a system of tokens or points can be devised. The tracking system should be 
carefully and colorfully displayed as a constant reminder of how much success the child has achieved. A large calendar posted in an obvious place works well. The tracking system should have set times when stickers, points, or tokens are rewarded, denied, or deducted. For instance, points can be awarded at the end of each class period, or at three designated times throughout the day, say at 10 a.m., 12 noon, and 2 p.m. There should also be opportunities for bonus points. Behavioral psychology research shows that the most effective type of reward is intermittent positive reinforcement. This means that a target behavior is most likely to increase when rewards are given periodically, on an intermittent basis. This principle also applies with slot machines in Las Vegas, where players feel compelled to keep dropping coins because they occasionally get rewarded and they never know when they might hit the jackpot.

Deduction of points is a possible option for not meeting behavioral targets. However, when first implementing a program it is advisable to defer using this option. When a child is demoralized and accustomed to lots of negative attention and failures, the goal initially is to focus on changing the tone, reversing the behavioral-teacher response dynamics. The idea is to catch these children being good and reward and praise them regularly and often. The attitude when children fail to meet their targets should be matter of fact ("Oh well"), not overly critical or punitive. For many children, not making their targets and failing to earn points and teacher approval and praise is punishment enough, and overt criticism just leaves them feeling depleted and demoralized. Deductions can be added at some point, but only if that option is first negotiated with all parties as an addition to the contract. It is important that nothing is added as a surprise to the child because he or she will feel cheated and disempowered if the teacher or parent makes up rules on the spot.

Competition is a powerful reinforcer, so it is helpful to have several or all students competing for tokens, points, and rewards. It is also helpful to use the concepts of peer pressure and team spirit in behavioral contracts. In addition to working for themselves, a class goal for a reward all classmates will enjoy together is helpful.

\section{Rewards Menu}

In developing a rewards menu, it is useful to get input from the child. Sometimes, parents and teachers think they know what kids want, but they could be wrong. Having children help develop their own rewards menus increases the likelihood that they will buy into the program and strive to comply with it. Often, parents are recruited to purchase or arrange for the rewards. The rewards selected should be very specificsomething in particular that the child is highly motivated to earn. The rewards can be material things, such as toys, games, or money, or things such as dinner at a favorite restaurant or a trip to the zoo. It's good to have options, with perhaps three different levels of awards, such as small, medium, and large, worth 50, 100, and 150 points, respectively. The child can choose to save up points for large rewards or turn them in early for small rewards. Having visual cues for the reward menu is helpful, such as a large poster that the child creates with pictures of possible rewards.

In addition to creating a large poster colorfully depicting potential rewards, construct a behavioral contract in writing. Successful behavioral contracts at school typically have approval from teachers, parents, and the students, and such contracts should be signed by all parties. Another feature of effective contracts is that they are kept simple-all parties are clear regarding the terms. Finally, it is helpful to acknowledge at the beginning that the contract may fail to result in modification of behavior and the contract may need to be modified and renegotiated. Figures 1 and 2 show sample contracts for addressing typical disruptive behaviors.

\section{STRATEGIES FOR IMPROVING ORGANIZATION AND PRODUCTIVITY}

Teachers can help children with ADHD by frequently reminding them to slow down and double-check their work to reduce the rate of careless errors. Children with ADHD are typically disorganized and tend to lose things and forget things necessary for schoolwork. They can be taught to

\section{'s Behavioral Contract}

Targets: 1. "I will speak only when it's my turn."

2. "I will follow directions by the count of 5 ."

3. "I will keep my hands and feet to myself."

Tracking: I will receive 1 point per target met at 10 a.m., 12 noon, and 2 p.m., for a possible total of 9 points per day.

My teacher will log the points into my log book and initial them three times per day.

I will review the log book with my parents each evening, and they will also track my points.

\begin{tabular}{lrl}
$\begin{array}{ll}\text { Rewards } \\
\text { Menu: }\end{array}$ & 50 Points $=$ Get to order pizza for dinner \\
& 100 Points $=$ Trip to bowling alley with Dad \\
& 150 Points $=$ Game for Nintendo \\
\hline
\end{tabular}

FIGURE 1

SAMPLE BEHAVIORAL CONTRACT FOR HOME AND SCHOOL 
's Behavioral Contract

Targets: 1. Complete and turn in homework daily

2. Complete and turn in classwork daily.

3. Attend all classes unless medically excused.

Tracking System:

1. must obtain signatures on day planner from all teachers whose classes were attended that day to verify classwork and homework completion and on-time submission. Teachers refuse to sign if homework or classwork is not completed or turned in.

2. must provide parent(s) with class schedule so signatures of appropriate teachers can be verified.

3. Day planner with signatures shown to parent(s) daily.

\section{Rewards System:}

1. For each day student meets all three targets, may have usual privileges (e.g., TV, time with friends, playing outside).

2. When reaches 30 days of compliance, may earn special outing (e.g., zoo, bowling, movies,

3. Each day fails to meet targets, confined to room, usual privileges revoked.

\section{Signatures:}

Parent

Student

Teacher

FIGURE 2

\section{SAMPLE CONTRACT FOR THE HOMEWORK/ SCHOOLWORK-NEGLIGENT CHILD}

maintain daily checklists in a special notebook or day planner of homework assignments. Initially, especially, they are likely to need coaching in developing these types of organizational methods.

Teachers can also assist children with ADHD by dividing their worksheets into sections and reducing their amounts of homework. Math problems and written assignments especially may prove extremely difficult and timeconsuming for children with ADHD, and reducing the quantity of these types of tasks is recommended. Another option teachers have is allowing extra time for children with ADHD to complete tests or in-school assignments. Following up with children with ADHD regarding incomplete or late assignments also increases their chances for success.

\section{REFERENCES}

Achenbach, T. M., \& Edelbrock, C. S. (1991). Manual for the child behavior checklist and child behavior profile. Burlington, VT: University of Vermont Department of Psychiatry.

Barkley, R. (1997). The defiant child: A clinician's manual for assessment and parent training. New York: Guilford Press.

Cantwell, D. (1996). Attention deficit disorder: A review of the past 10 years. Journal of the American Academy of Child and Adolescent Psychiatry, 35(8), 978-987.

Conners, C. K. (1997). Conners' rating scales: Instruments for use with children and adolescents (rev. ed.). New York: Multi-Health Systems, Inc.

Greene, R. (2001). The explosive child. New York: HarperCollins Publishers.

\section{PERMISSIONS AND COPYRIGHT}

All rights are reserved. No part of this publication may be reproduced, photocopied, faxed, stored in a retrieval system, or transmitted in any form or by any means, electronic, mechanical, recording or otherwise, without the prior written permission of the publisher.
Back issues are available for sale. Reproduction requires permission and payment of fees. It is illegal and a violation of federal copyright law to reproduce this publication without permission. Direct all inquiries to the permissions editor. 
Copyright of Focus on Exceptional Children is the property of Love Publishing $\mathrm{Co}$. and its content may not be copied or emailed to multiple sites or posted to a listserv without the copyright holder's express written permission. However, users may print, download, or email articles for individual use. 